\title{
Human anterior cingulate neurons and the integration of monetary reward with motor responses
}

Ziv M Williams, George Bush, Scott L Rauch, G Rees Cosgrove \& Emad N Eskandar

Nat. Neurosci. 7, 1370-1375 (2004)

A reference was deleted from this paper during the production process. It should have read as follows:

17. Botvinick, M., Nystrom, L.E., Fissell, K., Carter, C.S. \& Cohen, J.D. Conflict monitoring versus selection-for-action in anterior cingulate ¿ cortex. Nature 402, 179-181 (1999).

In addition, through a typographical error, a quotation mark was omitted from the last sentence of the legend for Table 1 . The correct version should read: Cumulative total from the "Reduced reward only" and the "Both reduced reward \& double arrow" categories represents all cells with significant response to reduced-reward trials.

CORRIGENDUM

\section{Motor activation prior to observation of a predicted movement}

James M Kilner, Claudia Vargas, Sylvie Duval, Sarah-Jayne Blakemore \& Angela Sirigu

Nat. Neurosci. 7, 1299-1301 (2004)

The affiliation given for Sylvie Duval was incorrect. The paper should have stated her affiliations as follows: Institut des Sciences Cognitives, CNRS, 67 Boulevard Pinel, 69675 Bron, France, and Department of Neuromotor Physiology, IRCCS- Fondazione Santa Lucia, Via Ardeatina 306, 00179 Roma, Italy. The authors regret the error. 